\title{
Couf_-940580--26
}

GA-A21716

\section{EFFECTS OF PARTICLE FUELING AND PLASMA WALL INTERACTIONS ON DIII-D DISCHARGES}

\author{
by \\ G.L. JACKSON, D.R. BAKER, K.L. HOLTROP, S. KONOSHIMA, ${ }^{*}$ \\ R. MAINGI, † G.M. STAEBLER, and W.P. WEST
}

This is a preprint of a paper to be presented at the Eleventh International Conference on Plasma Surface Interactions in Controlled Fusion Devices, May 23-27, 1994, Ibaraki-ken, Japan, and to be printed in the Proceedings.

Work supported by

U.S. Department of Energy

Contract No. DE-AC03-89ER51114

*Japan Atomic Energy Research Institute

toak Ridge National Laboratory

GENERAL ATOMICS PROJECT 3466

NOVEMBER 1994

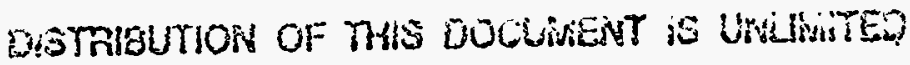

TJ

GENERAL ATOMICS

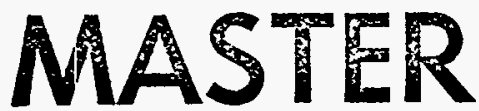




\section{DISCLAIMER}

This report was prepared as an account of work sponsored by an agency of the United States Government. Neither the United States Government nor any agency thereof, nor any of their employees, makes any warranty, express or implied, or assumes any legal liability or responsibility for the accuracy, completeness, or usefulness of any information, apparatus, produce, or process disclosed, or represents that its use would not infringe privately owned rights. Reference herein to any specific commercial product, process, or service by trade name, trademark, manufacturer, or otherwise, does not necessarily constitute or imply its endorsement, recommendation, or favoring by the United States Government or any agency' thereof. The views and opinions of authors expressed herein do not necessarily state or reflect those of the United States Government or any agency thereof. 


\section{DISCLAIMER}

Portions of this document may be illegible in electronic image products. Images are produced from the best available original document. 


\begin{abstract}
DIII-D has successfully operated with an all-graphite first wall, including the first observations of VH-mode without boronization. A major goal of this, and other recent upgrades, was to control impurity influxes and hydrogenic fueling. Graphite tiles were carefully preconditioned, first by ex situ preparation and then by baking and helium glow conditioning. No deuterium or hydrogen was used until tokamak operation commenced. With the all graphite wall, both impurity and deuterium influxes during tokamak discharges were lower than previous boronized discharges; central nickel impurity line radiation, NiXXV and NiXXVI, was an order of magnitude lower than previous discharges during the ELM free beam heated phase. The effect of reduced particle fueling on plasma performance, particularly $\mathrm{H}$ - and VH-mode discharges, will be presented.
\end{abstract}




\section{INTRODUCTION}

A major part of the DIII-D program is focused upon high performance experiments, such as $\mathrm{VH}$-mode and high $\beta_{\mathrm{N}}$ discharges, and rf heated experiments such as current drive discharges. An essential requirement for such experiments is low density and low impurity influx. In order to achieve such discharge conditions, DIII-D has had a continuing program to characterize and control plasma wall interactions (Jackson [1]). Beginning with the 1993 campaign, DIII-D has successfully operated with an all-graphite wall, dramatically reducing metal impurity accumulation without increasing the influx of low $\mathrm{Z}$ impurities. After installation of the allgraphite wall, the first VH-mode discharges without boronization were obtained and some of these discharges exhibited peaked density profiles and very low wall particle fueling.

With the improvement in impurity control obtained after installation of the all-graphite wall, control of the hydrogenic particles has received increasing attention. After discussing operation with the all-graphite wall, this paper will concentrate on analysis of the density rise during ELM free beam-heated phases of DIII-D discharges, namely high confinement mode ( $\mathrm{H}$-mode) and very high confinement mode ( $\mathrm{VH}$-mode). These phases have proven to be the most difficult to control. The relationship between particle fueling and the global particle time constant, $\tau_{\mathrm{g}}$ will also be discussed. 


\section{OPERATION AND DISCHARGE PERFORMANCE WITH AN ALL-GRAPHITE WALL}

Before the 1993 campaign, graphite coverage of plasma facing surfaces was increased from $45 \%$ to $90 \%$ and this change has significantly reduced the influx of metal impurities in DIII-D plasma discharges. Since graphite coverage is now limited only by port openings, we refer to this upgrade as the all-graphite wall. The graphite material used in DII-D is primarily Union Carbide type ATJ, a high density graphite.

Wall conditioning techniques were changed to accommodate the new graphite armor. Specifically, no hydrogen or deuterium was used during the vessel conditioning and vent recovery phase; only baking and helium glow cleaning. Since graphite coverage was increased from $45 \%$ to $90 \%$, there was concern that the increased carbon surface would contribute to additional low $Z$ and hydrogenic fueling. The increased surface area of the graphite can adsorb deuterium which can fuel the tokamak discharge, as well as contribute to chemical sputtering (e.g. $\mathrm{CD}_{4}$ ). This problem can become especially severe if the conditioning process itself changes the surface to a loosely bound layer of carbon, i.e. "soot," which might occur if large quantities of hydrocarbons are generated during the conditioning process. This may have been the cause of problems in obtaining H-mode in DIII-D at the start of the 1988 campaign when graphite surface coverage was increased from $9 \%$ to $40 \%$ (Jackson [2]). To avoid similar problems with the all-graphite wall, graphite tiles were carefully preconditioned. First, all surfaces of previously exposed tiles were grit blasted with $\mathrm{B}_{4} \mathrm{C}$ pellets (20-65 $\mu \mathrm{m}$ diameter) to remove the re-deposited surface layer containing significant amounts of metallic and other impurities and then all tiles were baked in a vacuum oven to $800-1000^{\circ} \mathrm{C}$ (Holtrop [3]).

The all-graphite wall was installed to reduce metal impurities. Previously, metal impurity accumulation was especially evident during $\mathrm{H}-$ and $\mathrm{VH}$-mode phases with long ELM free periods (Jackson $[1]$, ) and under some conditions a radiative collapse $\left(P_{\mathrm{rad}} / \mathrm{P}_{\mathrm{in}} \geq 1\right)$ occurred. While boronization significantly decreased the rate of rise of metallic impurities, radiated power due to these impurities could still be significant. With the all-graphite wall, tokamak discharges showed reductions in metal impurities by factors of $10-30$, most notably during the ELM free phase of $\mathrm{VH}$-mode discharges, when compared to previous $\mathrm{VH}$-mode discharges, e.g. Fig. 1. At the same time that the graphite coverage was increased, the backing plates between the graphite tiles and the Inconel wall were also changed from copper foam to GRAFOIL, a porous and compressible graphite material. This was done to eliminate random copper bursts caused by material from the backing plates falling into the plasma (see Fig. 1). The examples of impurity line radiation are shown in Fig. 1 as a relative comparison between the two wall configurations. Detailed modeling will be necessary to relate this impurity line radiation to plasma impurity 
concentration and $\mathrm{Z}_{\text {eff. }}$. In general, $\mathrm{Z}_{\mathrm{eff}}$ in DIII-D discharges is dominated by low $\mathrm{Z}$ impurities, usually carbon and oxygen, while metal impurity line radiation is the major source of radiated power (Wood [4]). It is significant that $Z_{\text {eff }}$ did not increase with the all-graphite wall during the ELM free phase even though the graphite surface area increased by a factor of 2 .
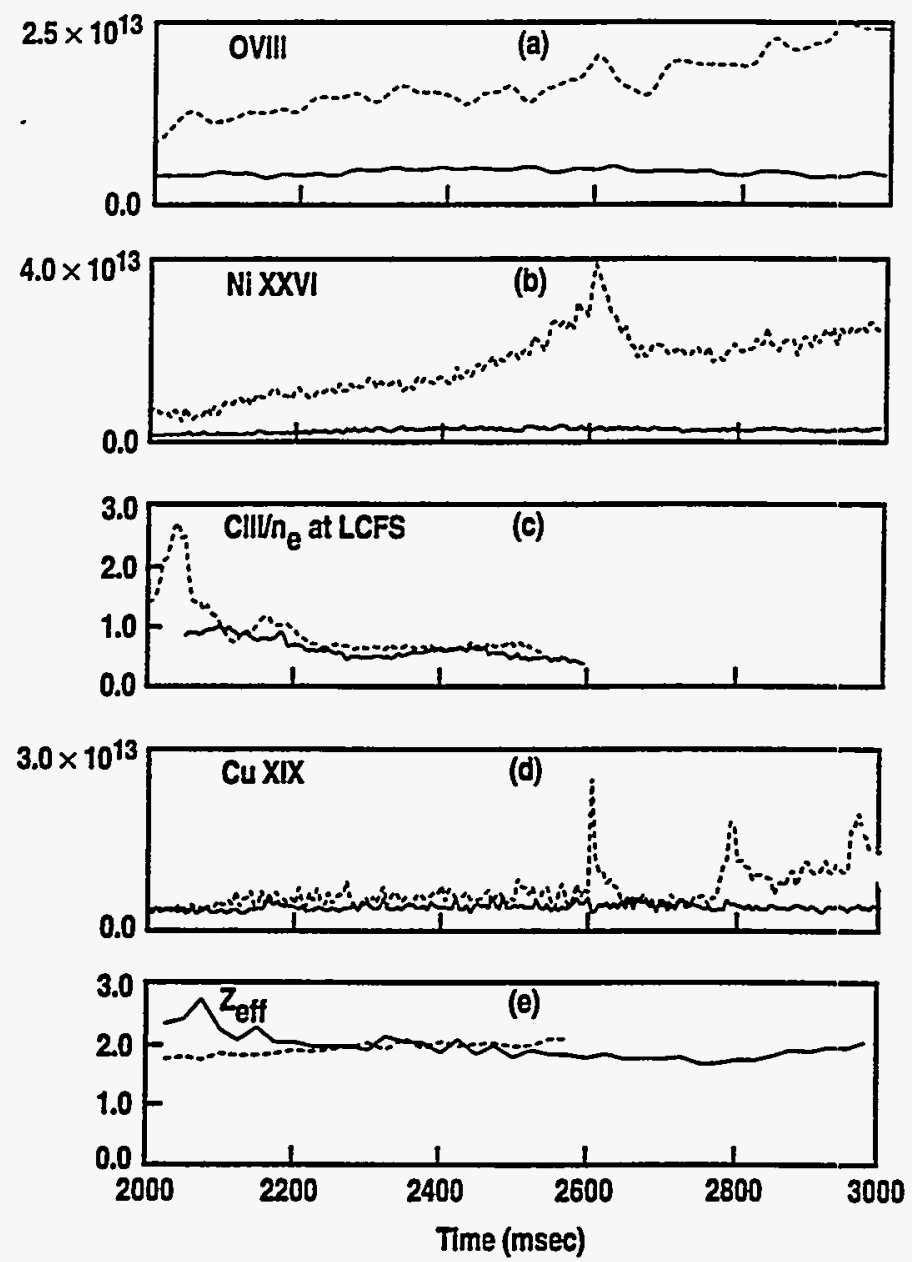

Fig. 1. Both oxygen (a) and metal impurity UV line radiation (b) are significantly reduced in discharges with the all-graphite wall (e.g. \#77074, solid lines) when compared to similar discharges from earlier campaigns (e.g. 1992, \#75121 dashed lines). No increase in either $Z_{\text {eff }}(e)$, or carbon line radiation normalized to edge density (c) is observed after installation of the all-graphite wall (double-null, 1.6 MA, 2.1 T, PNBI = $8 \mathrm{MW}$ ). Copper bursts seen previously (d) have not been observed with the all-graphite wall.

With the preconditioning described above and baking and helium glow conditioning, the allgraphite machine was rapidly commissioned. As shown in Table 1, the new conditioning procedure resulted in a much faster achievement of high confinement mode ( $\mathrm{H}$-mode) discharges as compared to early vents, even though the graphite coverage more than doubled. 
A further indication of the rapid machine recovery was the first observation of VH-mode without boronization. $\mathrm{VH}$-mode discharges are sensitive to wall conditions, requiring low target density, a low fraction of radiated power $\left(\mathrm{P}_{\mathrm{rad}} / \mathrm{P}_{\text {in }}<0.3\right)$, and $\mathrm{Z}_{\mathrm{eff}} \leqslant 2$. Not only were VH-mode discharges readily obtained with the unboronized all-graphite wall, but they exhibited lower recycling, inferred from $D_{\alpha}$ photodiodes, and peaked density profiles on some discharges.

\section{Table 1}

Machine Recovery time is substanially reduced with improved conditioning techniques after the 1992-1993 vent

\begin{tabular}{|c|c|c|}
\hline & $\begin{array}{c}\text { Recovery After } 1987 \text { Vent } \\
\text { (9\% To 40\% Graphite } \\
\text { Coverage) }\end{array}$ & $\begin{array}{l}\text { Recovery After 1992-1993 } \\
\text { Vent (45\% to } \sim 90 \% \\
\text { Graphite Coverage) }\end{array}$ \\
\hline Baking only & 130 hours & 47 hours \\
\hline $\begin{array}{l}\text { Baking and Taylor discharge } \\
\text { cleaning }\end{array}$ & $>70$ hours $\left(D_{2}\right)$ & 3.5 hours $(\mathrm{He})$ \\
\hline He glow with baking & & 3 hours \\
\hline $\begin{array}{l}\text { No. of tokamak discharges } \\
\text { before first } \mathrm{H} \text {-mode }\end{array}$ & 380 & 14. \\
\hline $\begin{array}{l}\text { HeGWC (helium glow wall } \\
\text { conditioning) before every } \\
\text { discharge }\end{array}$ & $\begin{array}{l}\text { Developed during vent } \\
\text { recovery period }\end{array}$ & Yes \\
\hline
\end{tabular}




\section{EFFECTS OF PARTICLE FUELING ON ELM FREE DISCHARGES}

Hydrogenic particle fueling sources in DIII-D can be categorized as external (neutral beam injectors and gas valves) or internal (particle desorption from plasma facing surfaces). For DIII-D discharges, internal fueling from the graphite tiles has been the dominant fueling source during the auxiliary heated phase of the discharge and reducing this source has proven to be one of the most difficult particle control problems for DIII-D. The ratio of total deuteron fueling, $\Gamma_{\text {tot }}$, to the fueling from the neutral beams, $\Gamma_{\text {beam, }}$, varies from 2 to greater than 6 after the $\mathrm{L}$ to $\mathrm{H}$ transition (Jackson [5]). Since there is no additional external fueling such as gas puff during the ELM free phase the additional fueling can only come from the walls.

The temporal behavior of plasma deuteron content, $N_{D}$ during the ELM free phase of DIII-D plasma discharges can be obtained from the particle balance equation:

$$
\frac{\mathrm{dN}}{\mathrm{d} t}=\Gamma_{\mathrm{NB}}+\Gamma_{\text {wall }}^{\mathrm{LCFS}}-\frac{\mathrm{N}_{\mathrm{D}}}{\tau_{\mathrm{g}}}
$$

where $\Gamma_{\mathrm{NB}}$ is the neutral beam particle flux (deuterons/s), $\Gamma_{\text {wall }}^{\mathrm{LCFS}}$ and the global particle time constant, $\tau_{\mathrm{g}}=\tau_{\mathrm{p}} /\left(1-\mathrm{R}^{\mathrm{LCFS}}\right)$, are assumed constant during the ELM free phase of a particular discharge (see Section 4). Note, however, that $\Gamma_{\text {wall }}^{\mathrm{LCFS}}$ and $\tau_{\mathrm{g}}$ vary from discharge to discharge. Since $N_{D}$ is the total number of plasma deuterons, we use the superscript LCFS to emphasize that these quantities are defined at the last closed flux surface (LCFS) and not the wall. In order to accurately represent the temporal evolution of the plasma deuteron content the term $\Gamma_{\text {wall }}^{\mathrm{LCFS}}$ was found to be necessary. We note that in the limit where $\Gamma_{\text {wall }}^{\mathrm{LCFS}}=0$, Eq. (1) reduces to the more conventional form [Tsuji, 6] and $\tau_{g}=\tau_{p}^{*}$, but such a single term fit with $\Gamma_{\text {wall }}^{\mathrm{LCFS}}=0$ does not adequately represent the DIII-D ELM free temporal deuteron evolution.

The solution to Eq. (1) is:

$$
\mathrm{N}_{\mathrm{D}}=\left(\Gamma_{\text {wall }}^{\mathrm{LCFS}}+\Gamma_{\mathrm{NB}}\right) \tau_{\mathrm{g}}+\left[\mathrm{N}_{\mathrm{D}}(0)-\left(\Gamma_{\text {wall }}^{\mathrm{LCCS}}+\Gamma_{\mathrm{NB}}\right) \tau_{\mathrm{g}}\right] \mathrm{e}^{-\mathrm{t} / \tau_{\mathrm{g}}}
$$

where the deuteron content is obtained from plasma volume (MHD equilibrium fitting code EFIT) and profiles of electron density (Thomson scattering and $\mathrm{CO}_{2}$ laser interferometry), electron temperature (Thomson scattering), and $Z_{\text {eff (visible brehmstrallung). As displayed in }}$ Fig. 2, the temporal density evolution is well represented by Eq. (2) assuming that $\tau_{\mathrm{g}}$ is constant. A test of this assumption can be made by substituting the fitted term $\Gamma_{\text {wall }}^{\mathrm{LCFS}}$ into Eq. (1) and solving for $\tau_{g}(t)$. This is shown in Fig. 2 where $\tau_{g}$ is approximately constant over the fitting 
interval. Note that there is no increase in $\tau_{\mathrm{g}}$ at the $\mathrm{VH}$-mode transition time, $\mathrm{t}=2370 \mathrm{~ms}$, where energy confinement begins increasing.

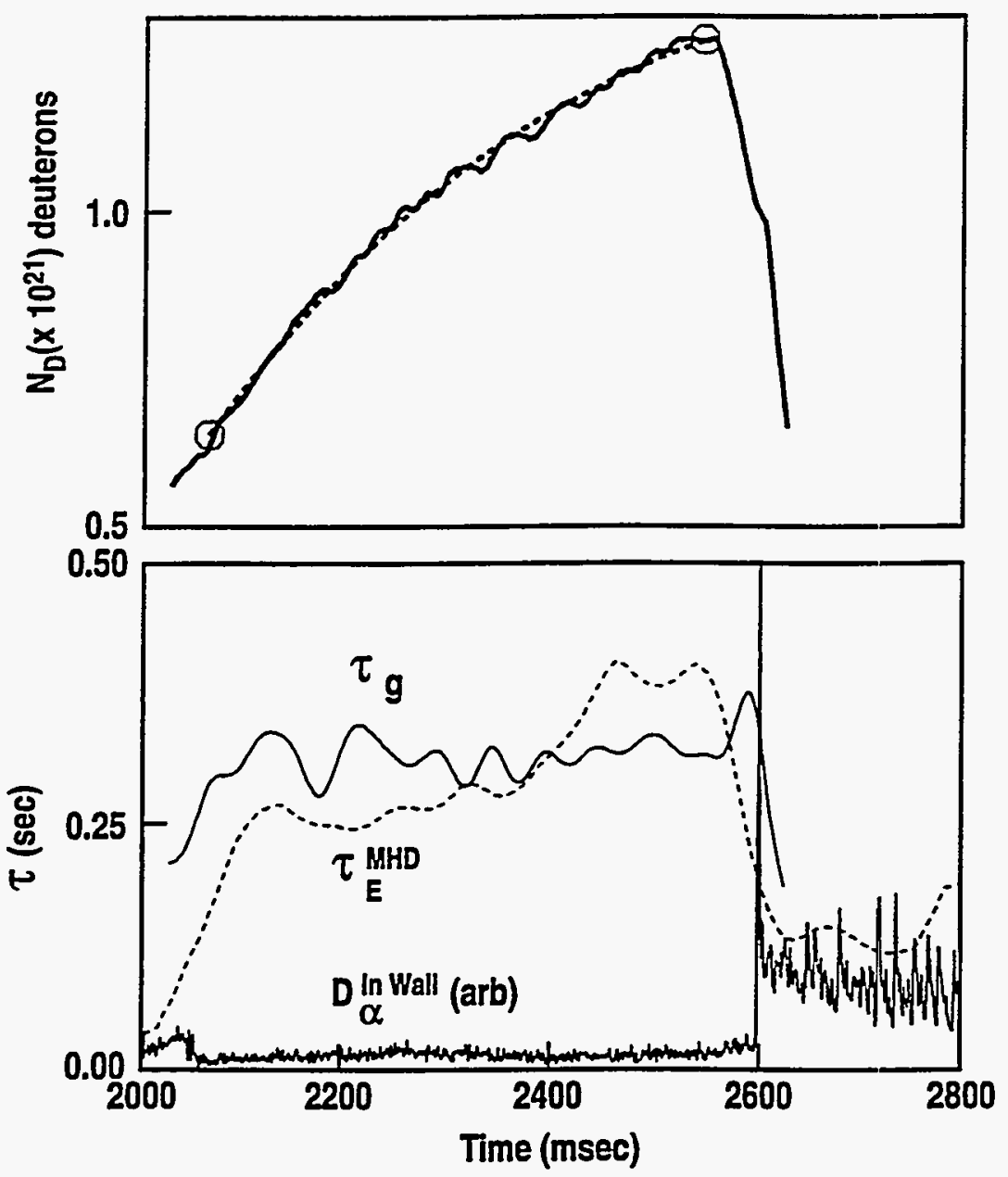

Fig. 2. Deuteron particle content, $N_{D}$ (solid line), is fit well by Eq. (2), dashed line, after the $\mathrm{L}$ to $\mathrm{H}$ transition (vertical line at $2050 \mathrm{~ms}$ ). The range of the fit is denoted by circles. There is no increase in $t_{g}$ at the transition from $\mathrm{H}$-mode to $\mathrm{VH}$-mode when $\tau_{E}$ begins increasing at $2370 \mathrm{~ms}$, shown by vertical line. Neutral beam injection started at 2000 $\mathrm{mSec}$ (discharge \#75121).

Several factors control wall condition and hence fueling including: helium glow, ohmic target density (which is a function of gas fueling and the details of the discharge startup phase), wall composition, discharge shape, and external pumping. The effects of the first three factors on $\tau_{\mathrm{g}}$ are shown in Fig. 3. When the duration of the helium glow between discharges is increased, $\Gamma_{\text {wall }}^{\mathrm{LCFS}}$ decreases. Although not plotted, the decrease in $\Gamma_{\text {wall }}^{\mathrm{LCFS}}$ is accompanied by a reduction in the $\mathrm{D}_{\alpha}$ line emission. In another scan in Fig. 3 , as the ohmic target density is decreased, $\Gamma_{\text {wall }}^{\mathrm{LCFS}}$ again decreases. Also plotted in Fig. 3 are two discharges obtained immediately after the wall composition was changed to all-graphite. These discharges exhibited the lowest values of $\Gamma_{\text {wall }}^{\mathrm{LCFS}}$ 
observed so far for 1.6 MA VH-mode discharges. In all of these cases as wall fueling is reduced (lower $\Gamma_{\text {wall }}^{\mathrm{LCFS}}$ ) $\tau_{\mathrm{g}}$ increases and is well fit by the relation:

$$
\Gamma_{\text {wall }}^{\mathrm{LCFS}} \times \tau_{\mathrm{g}}=1.32 \pm 0.10 \times 10^{21} \text { deuterons }
$$

It should be emphasized that the data shown in Fig. 3 is for a specific set of discharges: 1.6 MA, high triangularity double-null diverted discharges. The effect of shape, current, and toroidal field has not been determined.

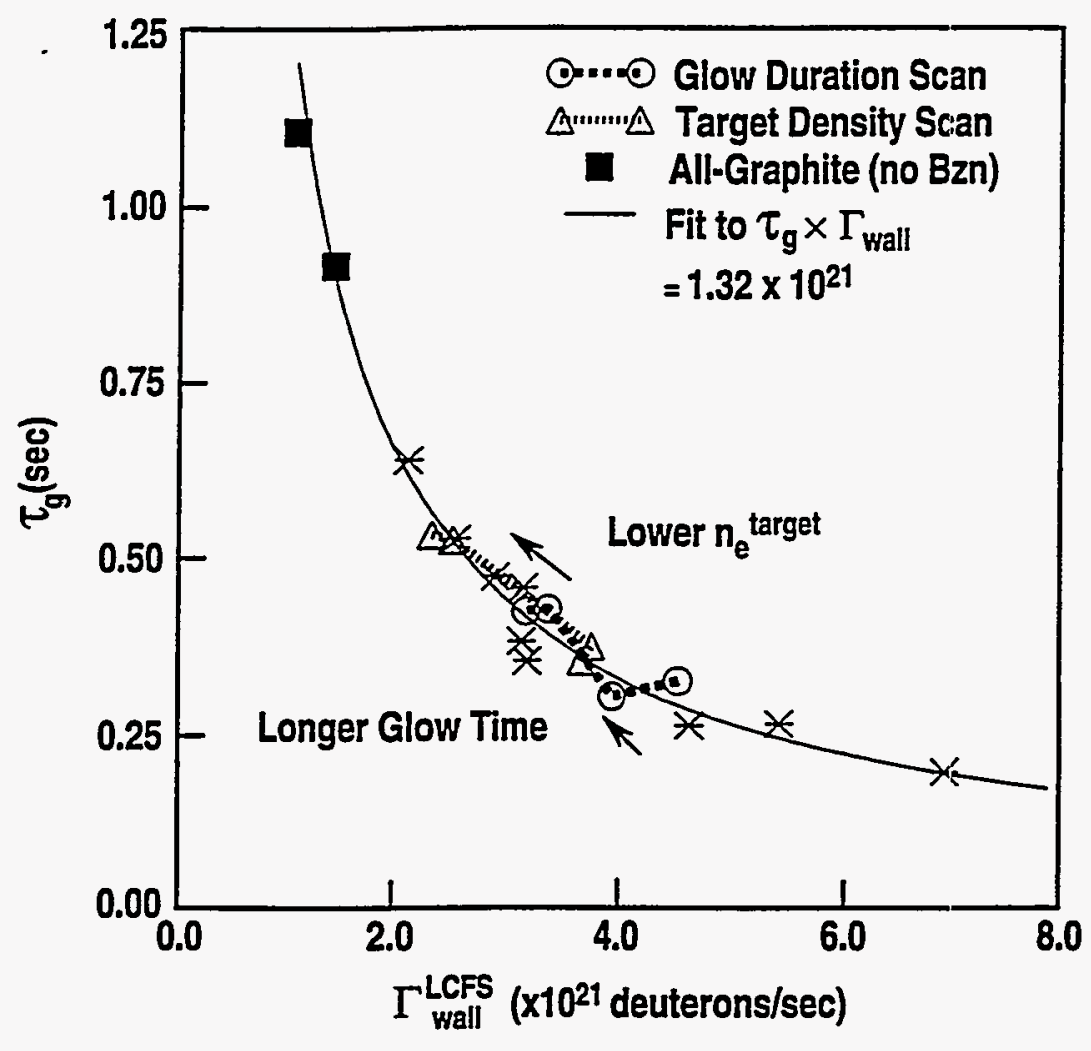

Fig. 3. $\tau_{g}$ increases as the particle source term $\Gamma_{\text {wall }}^{\mathrm{LCF}}$ decreases. The lowest values of $\Gamma_{\text {wall }}^{\mathrm{LCFS}}$ were obtained with the all-graphite wall (solid squares). $\Gamma_{\text {wall }}^{\mathrm{LCFS}}$ decreases with longer glow duration (dashed line and circles) and lower ohmic target density (dotted line and triangles). $\Gamma_{\text {wall }}^{\mathrm{LCFS}}$ and $\tau_{\mathrm{g}}$ are determined by fits to the deuteron particle content Eq. (2) during the ELM free phase of each discharge shown in this figure. 


\section{DISCUSSION}

Operation of DIII-D with all graphite walls has reduced high $Z$ impurity influxes without increases in low $Z$ impurities. As shown in Fig. 1, the carbon influx did not increase during the 1993 campaign, even though the graphite coverage doubled. At least two factors have contributed to this. First, the exclusive use of baking and helium glow discharge conditioning has minimized hydrocarbon production. We speculate that this also reduced the amount of loosely bound carbon on the plasma facing surfaces and hence minimized the wall as a source of both carbon impurity influx and deuterons for tokamak discharges. Second, oxygen influx, inferred from UV line emission, was also reduced by factors of 2 to 3 as shown in Fig. 1 and (Wood [4). A reduction in oxygen can lead to reductions in other low $Z$ impurities (Winter [7]). Thus the potential for an increase in the carbon influx due to the increased graphite surface area may have been offset by the reduction in oxygen. One explanation for the oxygen reduction is the careful tile pre-conditioning which was described in Section 2 and (Holtrop [3]). The discharges with the lowest particle fueling in Fig. 3 were obtained immediately after beginning operation with the all-graphite wall. Similar discharges after several weeks of operation did not show the same low values of particle fueling or density peaking. Oxygen influx increased during this period and this may account for the increased particle fueling and a return to flat $\mathrm{VH}$-mode density profiles.

The physical interpretation of $\Gamma_{\text {wall }}^{\mathrm{LCFS}}$ is still under investigation. In this zero order model we have assumed $\Gamma_{\text {wall }}^{\mathrm{LCFS}}$ and $\tau_{\mathrm{g}}$ are constants. A constant $\Gamma_{\text {wall }}^{\mathrm{LCFS}}$ term was motivated, in part, by the observation that the $D_{\alpha}$ line emission viewed away from the strike points is nearly constant during the ELM free period, as plotted in Fig. 2. This temporal behavior is observed at: a) the outer wall (fast neutral pressure gauge), b) the outer midplane (Lyman $D_{\beta}$ emission), c) the outer floor and ceiling which are away from the divertor strike points ( $D_{\alpha}$ photodiodes), and $d$ ) the inner wall ( $D_{\alpha}$ photodiodes). This behavior is qualitatively consistent with a model that the recycling particle flux, $\mathrm{RLCFS} \times \mathrm{N}_{\mathrm{D}} / \tau_{\mathrm{p}}$, originates near the divertor strike points while a more constant particle fueling term, represented by $\Gamma_{\text {wall }}^{\text {LCFS }}$, originates from particles desorbed from graphite surfaces away from the divertor regions. It is perhaps surprising that such good agreement with the temporal evolution of $N_{D}$ is obtained with such a simple model. However we note that more detailed models using $\Gamma_{\text {wall }}^{\mathrm{LCFS}}(\mathrm{t}), \tau_{\mathrm{g}}(\mathrm{t})$, or a wall reservoir can also provide good fits to Eq. (2) (Owen, Jones [8], [9]). The differences in the various models are currently under investigation. In all cases, however, an additional term is necessary in the particle balance equation to adequately fit the ELM free deuteron temporal behavior, and the physical origin of this term must be a source of particles originating from the wall. Furthermore, very high 
confinement (VH-mode) discharges can only be obtained when this wall source term is sufficiently low.

The data shown in Fig. 3 implies that there is a correlation between $\tau_{\mathrm{g}}$ and a wall source term, $\Gamma_{\text {wall }}^{\mathrm{LCFS}}$. For the 1.6 MA DND discharges presented in Section 3 we find that $\tau_{\mathrm{g}} \times \Gamma_{\text {wall }}^{\mathrm{LCFS}}=1.32 \times 10^{21}$ is a good approximation for fits to the deuteron particle content during the ELM free phase of these discharges. In all discharges shown in Fig. 3 except the two with the unboronized graphite wall, $\Gamma_{\text {wall }}^{\mathrm{LCFS}} \gg \Gamma_{\mathrm{NB}}$. Thus, $\tau_{\mathrm{g}} \times \Gamma_{\text {wall }}^{\mathrm{LCFS}} \sim 1.32 \times 10^{21}$ deuterons is the dominant term in Eq. (2) which determines the steady state density, $N_{D} / V_{P}$, that a discharge would reach in the absence of ELMs, MHD, or discharge termination.

It may seem surprising $\tau_{\mathrm{g}}$ would increase as wall fueling decreases (Fig. 3) since less wall fueling usually implies that the walls are pumping better and hence recycling is lower. However as $\Gamma_{\text {wall }}^{\mathrm{LCFS}}$ decreases the SOL density is reduced in these discharges and neutral particle penetration increases. Since the particle replacement time, $\tau_{p}$, is a function of the effective penetration length, we would expect deeper penetration to increase particle confinement time (Tsuji [6]). If the recycling coefficient, $\mathrm{R}^{\mathrm{LCFS}}$, does not change appreciably, then $\tau_{\mathrm{g}}$ will also increase. The term $\Gamma_{\text {wall }}^{\text {LCFS }}$ represents a flux of particles at the LCFS. It is a function of the particle desorption rate from the graphite tiles and the penetration probability of these particles from the wall to the LCFS. Hence for discharges where particle penetration increases and $\Gamma_{\text {wall }}^{L C C S}$ decreases, the wall particle source must be reduced by an even larger factor than $\Gamma_{\text {wall }}^{\mathrm{LCFS}}$. 


\section{CONCLUSIONS}

DIII-D has successfully operated with an all-graphite wall which has minimized high $Z$ impurity influxes without increasing low $Z$ impurities. By carefully preconditioning the graphite tiles and using only baking and helium glow conditioning, deuteron wall fueling rates have been reduced to the lowest values yet obtained on DII-D and unboronized VH-mode discharges have been obtained for the first time.

Many factors can affect wall condition, particle fueling, and hence the deuteron behavior, but we find that $\tau_{\mathrm{g}} \times \Gamma_{\text {wall }}^{\mathrm{LCFS}}=1.32 \times 10^{21}$ deuterons for the set of $1.6 \mathrm{MA}$ discharges presented in this paper. Lower particle fueling (lower $\Gamma_{\text {wall }}^{\mathrm{LCFS}}$ ) implies a larger $\tau_{\mathrm{g}}$ requiring a longer time for the density to reach its equilibrium value. With the analysis described in this paper, there is no increase in $\tau_{\mathrm{g}}$ at the $\mathrm{H}$ - to $\mathrm{VH}$-mode transition, where the energy confinement time increases (see Fig. 2). This observation is consistent with a picture that particle confinement is dominated by a strong reduction in the particle diffusivity very near the LCFS where the H-mode transport barrier occurs (Groebner [10]). The region for VH-mode energy confinement improvement occurs further inside the LCFS beyond the region of significant penetration for low energy neutral deuterons where a "spin-up" is observed in plasma rotation resulting in a region of increased radial shear (Osborne [11]).

In present day devices highest confinement is generally obtained with low particle fueling and low recycling[12]. Future work on the DIII-D tokamak will explore ITER relevant configurations such as enhanced confinement regimes (which requires control of particle fueling from the main chamber) with a radiative divertor. 


\section{REFERENCES}

[1] G.L. Jackson and the DIII-D Team, J. Vac. Sci. and Technol. A 10 (1992) 1244.

[2] G.L. Jackson, T.S. Taylor, and P.L. Taylor, Nucl. Fusion 30, (1990) 2305.

[3] K.L. Holtrop, G.L. Jackson, A.G. Kellman, et. al., General Atomics Report GA-A21487 (1993), to be published in J. Vac. Sci. Technol. A (1994).

[4] R. Wood, Bull. Am. Phys. Soc. 38 (1993) 2064.

[5] G.L. Jackson, J. Winter, K.H. Burrell, et .al., J. Nucl. Mater. 196-198 (1992) 236.

[6] S. Tsuji, Fus. Engr. and Des. 15 (1992) 311.

[7] J. Winter. J. Nucl. Mater. 176-177 (1990) 14.

[8] Owen, L.W., et. al., these proceedings.

[9] T.T.C. Jones, J.W. Cuthbertson, J. Ehrenberg, et al., J. Nucl. Mater. 162-164(1989)503.

[10] R.J. Groebner, Phys. Fluids B 5 (1993) 2343.

[11] T.H. Osborne, K.H. Burrell, T.N. Carlstrom, et. al., General Atomics Report GA-A21182 (1992), submitted to Nuc. Fus.

[12] S. Itoh, these proceedings. 


\section{ACKNOWLEDGMENT}

This work was supported by the U.S. Department of Energy under Contract Nos. DE-AC03-89ER51114 and DE-AC05-84OR21400. 